\title{
StarDust: um serious game para a aprendizagem implícita de grafos
}

\author{
Rafaela Melo ${ }^{1}$, Douglas Silva ${ }^{1}$, Fernanda Pires ${ }^{1}$ \\ ${ }^{1}$ Universidade do Estado do Amazonas (UEA) - Licenciatura em Computação \\ Laboatório de Pesquisa e Desenvolvimento em Tecnologias educacionais (ThinkTEd) \\ Manaus - AM - Brazil \\ $\{$ rmf.lic16,dsm.lic17,fpires\}@uea.edu.br
}

\begin{abstract}
Resumo. O presente artigo trata do desenvolvimento do serious game educacional StarDust. Voltado para plataformas móveis e de gênero puzzle, o jogo é ambientado no espaço e tem como foco a aprendizagem de grafos. A abordagem implícita pretende mostrar uma visualização lúdica do problema do caminho mínimo para estudantes da área da computação. A mecânica e gameplay de StarDust permite que seja jogado por públicos de qualquer idade, mas o desconhecimento de conceitos computacionais pode levar a classificação do jogo como casual. O jogo foi desenvolvido em linguagem C\# com a engine Unity $2 D$ e seus gráficos foram criados à partir de composição.
\end{abstract}

\section{Cenário de Uso}

Disciplinas que envolvem programação no ensino superior na área de Exatas são consideradas desafiadoras, posto que demandam o desenvolvimento de estratégias com base lógica-matemática para solucionar problemas [Deters et al. 2008] que nem sempre foram exercitadas anteriormente. Essas dificuldades acabam resultando em altos índices de reprovação na grade de programação, por isso, professores e pesquisadores têm procurado formas de auxiliar na mudança deste cenário [Chaves et al. 2013].

Jogos de computador, videogames ou jogos para celular são em sua maioria desenvolvidos para o entretenimento e contam com um alto número de consumidores. Considerando isso, nos últimos anos surgiram propostas de aplicação de jogos a outros campos de conhecimento como: saúde, publicidade, comunicação, política, religião e educação, tais jogos foram denominados serious game [Abt 1987, Alvarez et al. 2019].

Serious Game tem por objetivo incentivar os jogadores a desenvolver habilidades que estão atreladas a algum conteúdo específico, arquitetando jogadas que não envolvem apenas aspectos tradicionais de jogos, mas também, aspectos específicos do contexto sério tratado, que pode ser conteúdo escolar [Charsky 2010]. Um serious game deve ser atraente e divertido como os demais jogos de entretenimento, é importante que exista um equilíbrio entre as duas partes [Michael and Chen 2005, Arnab et al. 2015].

Nos últimos anos, serious game têm sido desenvolvidos em diferentes campos do conhecimento, inclusive em Ciência da Computação, como em Robocode e CoLoBoT [Arnab et al. 2015]. No entanto, a maioria desses jogos se limitam a aprendizagem de linguagens de programação, ou então para estimular o desenvolvimento de lógica computacional. Apesar disso, trabalhos recentes apresentam jogos que abordam aspectos mais complexos da ciência da computação, neste caso, a teoria dos grafos [Yang et al. 2016, Chiang and Yang 2017]. 
VIII Congresso Brasileiro de Informática na Educação (CBIE 2019)

Anais dos Workshops do VIII Congresso Brasileiro de Informática na Educação (WCBIE 2019)

O presente trabalho tem por objetivo apresentar um serious game educacional do gênero puzzle, intitulado StarDust. O jogo em sua primeira versão aborda o problema do caminho mínimo, de Teoria dos Grafos. A aprendizagem implícita permite que este jogo não se limite ao público alvo de alunos de nível superior, pode ser aplicado com crianças também, mas para que seja efetivo precisa de ajustes para atender ambos os públicos.

\section{Desenvolvimento}

Essa seção trata do processo seguido para o desenvolvimento do jogo, bem como as ferramentas e a metodologia utilizadas.

\subsection{Processo de desenvolvimento}

O processo de desenvolvimento levou em conta um ciclo de vida iterativo-incremental, com cinco etapas principais, descritas na Figura 1.

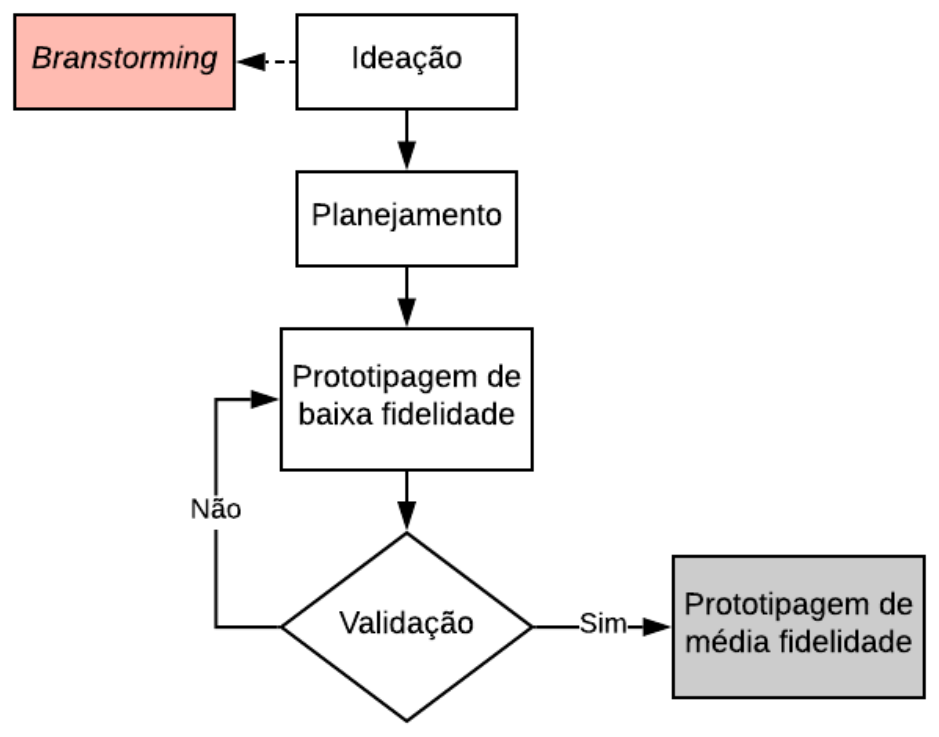

Figura 1. Processo de desenvolvimento

\subsubsection{Ideação}

Nesta etapa foi analisado e discutido como ludificar o processo de aprendizagem de grafos utilizando um jogo educacional. No processo de brainstorming foram consideradas as especificidades do tema, o ciclo de aprendizagem, o processamento da informação humano, e as características do público alvo. Para organizar a ideação do jogo começaram as discussões em torno de: storytelling, mecânica, artes do jogo, sistema de pontuação e personagens.

\subsubsection{Planejamento}

A etapa de planejamento determina como e com que ferramentas as etapas do processo serão realizadas. Para fins de documentação, utilizou-se uma adaptação do GDD - Game 
VIII Congresso Brasileiro de Informática na Educação (CBIE 2019)

Anais dos Workshops do VIII Congresso Brasileiro de Informática na Educação (WCBIE 2019)

Design Document [Rogers 2014], este documento se manteve ativo durante todo processo de desenvolvimento, incluindo diversas informações referentes ao jogo: mecânica, design (game art), personagens, etc.

\subsubsection{Prototipação}

O processo de prototipagem de baixa fidelidade foi realizado no papel com a finalidade de visualizar os aspectos discutidos na fase de idealização. O protótipo de média fidelidade (também versão mais recente do jogo) foi desenvolvido na Game Engine Unity, utilizando todo o design e telas definidas, além da mecânica implementada.

\subsubsection{Validação}

Diversos processos são necessários para validar se um jogo educacional é eficaz ou não. Primeiramente, o jogo passou por um designer de aprendizagem, para analisar se os aspectos do jogo condizem com os princípios de aprendizagem necessários. Como o jogo está em fase de desenvolvimento, estão sendo realizadas avaliações de usabilidade e comunicabilidade.

\subsection{Ferramentas utilizadas}

As ferramentas utilizadas para desenvolvimento do jogo foram:

- Editores de texto para a documentação do jogo;

- Editores gráficos para manipulação de imagens utilizadas no jogo;

- Unity para o desenvolvimento do protótipo funcional (média fidelidade).

\section{Apresentação do software}

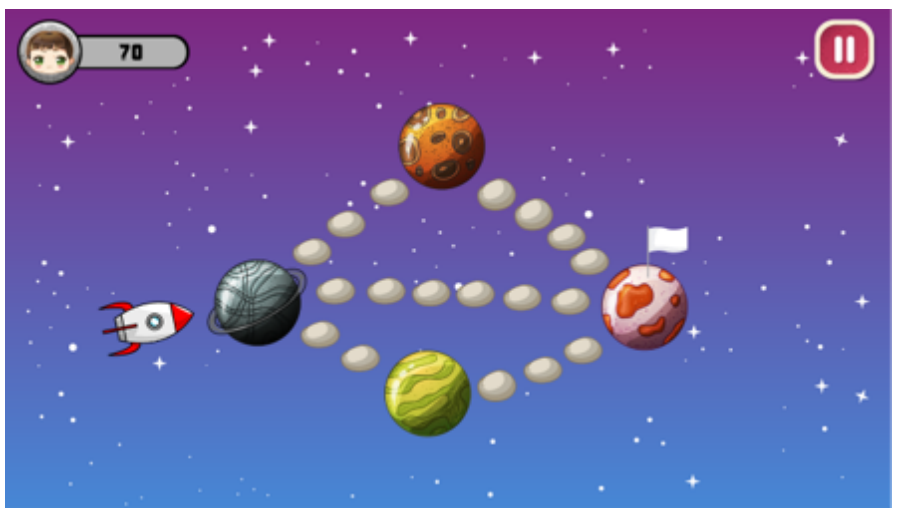

Figura 2. Jogo StarDust

StarDust (Figura 2) é um jogo puzzle para plataformas móveis Android, voltado para a aprendizagem e aplicação do conceito de caminho mínimo em grafo. Por abordar este conceito de forma implícita, pode ser utilizado por pessoas de diversas idades, visto que não necessita de nenhum conceito prévio próprio da área da computação. 


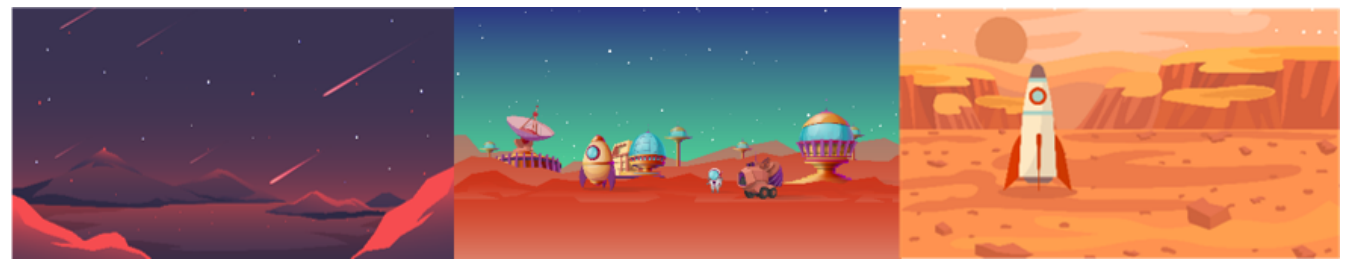

Figura 3. Backgrounds usados no storytelling

\subsection{História do jogo}

A explosão de uma galáxia deixou o universo em pleno caos. Seus vestígios em forma de poeira cósmica espalharam-se por parte do universo. As galáxias que não foram afetadas criaram uma frota intergaláctica para oferecer apoio aos sistemas e planetas (Figura 4) que entraram em desordem. Alice (Figura 5), recebeu a missão de comandar a nave responsável por levar suprimentos para o setor sul do universo, começando pela galáxia Minimex. No entanto, o combustível da nave é limitado. Por isso, a capitã Alice precisará de sua ajuda para completar sua missão e percorrer todos os planetas de Minimex, gastando a menor quantidade possível de combustível.

\subsection{Design do jogo}
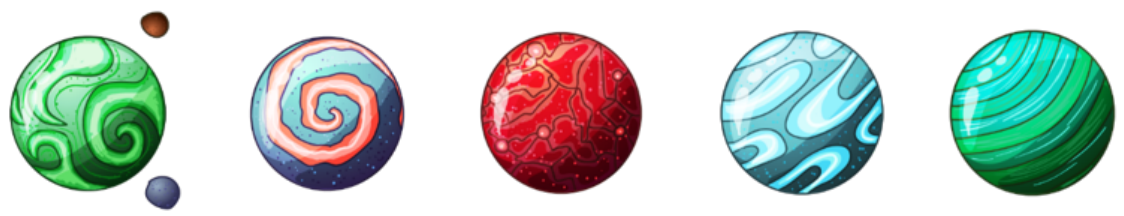

Figura 4. Exemplos de Planetas utilizados nas fases

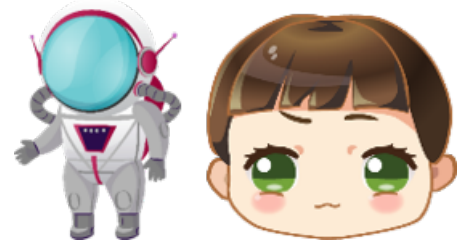

Figura 5. Representação de Alice, no Storytelling e ao longo do jogo

O design do jogo foi criado à partir de técnicas de composição, utilizando assets disponíveis na Internet, em sites como: Craftpix, Freepik, Kenney e Game Art 2D. Todas as game arts foram selecionadas por tema espacial, principalmente os backgrounds que compuseram a storytelling do jogo (Figura 3).

\subsection{Mecânica do jogo e o problema do caminho mínimo}

Na computação, o problema do caminho mínimo trata do custo de travessia entre dois nós (vértices), o custo é dado pela soma dos pesos das arestas. No jogo, implicitamente, a resolução do problema incentiva a utilização do algoritmo do caminho mínimo.

A versão atual do jogo conta com uma galáxia (fase). Para vencer cada um dos desafios dentro de Minimex, é preciso chegar ao planeta destino (representado por uma 
VIII Congresso Brasileiro de Informática na Educação (CBIE 2019)

Anais dos Workshops do VIII Congresso Brasileiro de Informática na Educação (WCBIE 2019)

bandeira). Para fazer com que a nave vá de um planeta ao outro, basta clicar em um dos planetas adjacentes ao planeta atual, até que chegue ao destino final.

As subfases dentro do desafio principal elevam a dificuldade progressivamente. Em sua primeira vez jogando, o usuário possui apenas uma fase desbloqueada. Para desbloquear as demais, é preciso completar o problema anterior, e assim subsequentemente.

Condição de vitória: O jogador precisa economizar o máximo de combustível possível, ou seja, precisa traçar o menor caminho entre o planeta inicial e o planeta final. A distância entre os pontos no jogo é representada por asteroides (pedras), cada um deles vale 10 pontos de combustível, ou seja, para vencer a fase, é preciso traçar o caminho que passe pelo menor número de asteroides possível.

O jogador usa o conceito do caminho mínimo para ir de uma planeta inicial a um planeta destino, identificado por uma bandeira. A quantidade de asteroides entre um planeta e outro, é considerado o peso de uma aresta.

\section{Considerações finais}

$\mathrm{O}$ artigo apresentou o jogo StarDust, que tem como principal objetivo auxiliar na aprendizagem de grafos de forma lúdica para diferentes públicos, uma vez que se tem um equilíbrio entre diversão e aprendizagem, mesmo que os jogadores não estejam familiarizados com conceitos de grafos é possível que se tenha uma boa experiência.

Pretende-se futuramente desenvolver novas fases para o jogo, abordando outros problemas computacionais, afim de apresentá-lo para usuários externos testarem e através dos resultados obtidos, refinar cada vez mais o jogo, até estar de acordo com os requisitos definidos para liberar o jogo em algumas plataformas.

\section{Referências}

Abt, C. C. (1987). Serious games. University press of America.

Alvarez, J., Irrmann, O., Djaouti, D., Taly, A., Rampnoux, O., and Sauve, L. (2019). Design games and game design: Relations between design, codesign and serious games in adult education. pages 229-253.

Arnab, S., Lim, T., Carvalho, M. B., Bellotti, F., De Freitas, S., Louchart, S., Suttie, N., Berta, R., and De Gloria, A. (2015). Mapping learning and game mechanics for serious games analysis. 46(2):391-411.

Charsky, D. (2010). From edutainment to serious games: A change in the use of game characteristics. 5(2):177-198.

Chaves, J. O., Castro, A., Lima, R., Lima, M. V., and Ferreira, K. (2013). Mojo: uma ferramenta para auxiliar o professor em disciplinas de programação. In Congresso Brasileiro de Ensino Superior a Distância, Belém, PA.

Chiang, H.-Y. and Yang, M.-C. (2017). On developing the online hamilton cycles learning games with the design considerations of learning reflexiveness. In 2017 International Conference on Applied System Innovation (ICASI), pages 1954-1956. IEEE.

Deters, J. I., da Silva, J. M. C., de Miranda, E. M., and Fernandes, A. (2008). O desafio de trabalhar com alunos repetentes na disciplina de algoritmos e programação. In Workshop de Ambientes de apoio a Aprendizagem de Algoritmos e Programação. 
VIII Congresso Brasileiro de Informática na Educação (CBIE 2019)

Anais dos Workshops do VIII Congresso Brasileiro de Informática na Educação (WCBIE 2019)

Michael, D. R. and Chen, S. L. (2005). Serious games: Games that educate, train, and inform. Muska and Lipman/Premier-Trade.

Rogers, S. (2014). Level Up The guide to great video game design. John Wiley \& Sons.

Yang, M.-C., Xu, Z.-T., and Hsu, L.-H. (2016). On developing the learning game for graph theory: A new design model considering the learners' reflexiveness. In 2016 5th IIAI International Congress on Advanced Applied Informatics (IIAI-AAI), pages 418-422. IEEE. 